\begin{tabular}{|l|l|l|}
\hline \multicolumn{2}{|c|}{ PublisherInfo } \\
\hline \hline PublisherName & $:$ & BioMed Central \\
\hline \hline PublisherLocation & $:$ & London \\
\hline \hline PublisherImprintName & $:$ & BioMed Central \\
\hline \hline
\end{tabular}

\title{
ATM phosphorylates BRCA1
}

\begin{tabular}{|l|l|l||}
\hline \multicolumn{2}{|c|}{ ArticleInfo } \\
\hline \hline ArticleID & $:$ & 3663 \\
\hline \hline ArticleDOI & $:$ & $10.1186 /$ bcr-1999-66641 \\
\hline \hline ArticleCitationID & $:$ & 66641 \\
\hline \hline ArticleSequenceNumber & $:$ & 29 \\
\hline \hline ArticleCategory & $:$ & Paper Report \\
\hline \hline ArticleFirstPage & $:$ & 1 \\
\hline \hline ArticleLastPage & $:$ & 4 \\
\hline \hline & & RegistrationDate : 1999-11-17 \\
ArticleHistory & $:$ & OnlineDate $\quad$ 1999-11-17 \\
\hline \hline ArticleCopyright & $:$ & Current Science Ltd1999 \\
\hline \hline ArticleGrants & $:$ & \\
\hline \hline ArticleContext & $:$ & 1305822 \\
\hline \hline
\end{tabular}




\section{Keywords}

ATM, BRCA1, DNA damage, mass spectroscopy, phosphorylation

\section{Introduction}

Heterozygous carriers of mutant $B R C A 1$ or $A T M$ genes have been reported to be predisposed to breast cancer. The ATM gene product, which is related to the phosphoinositide kinase family, is activated in response to DNA damage and is required for efficient DNA double-strand break repair. Studies in mice have demonstrated a role for Brcal in the repair of DNA double-strand breaks, whilst analysis of the human BRCA1 protein have shown it becomes phosphorylated in response to DNA damage.

\section{Aims}

To test whether ATM is required for phosphorylation of BRCA1 in response to DNA damage.

\section{Comments}

This paper puts BRCA1 downstream of ATM in a pathway involved in the cellular response to gamma-irradiation. It has been estimated that $6.6 \%$ of all breast cancers occur in $A T M$ heterozygotes, whilst up to $3 \%$ of breast cancers occur in BRCA1 heterozygotes. Breast cancer predisposition in ATM heterozygotes is still controversial but, if true, mutations in an ATM-BRCA1 DNA repair pathway could account for as much as $10 \%$ of all breast cancers.

\section{Methods}

Association of BRCA1 and ATM was assayed by co-immunoprecipitation from HeLa cells. Phosphorylation of BRCA1 or BRCA1 fragments was analysed by mobility shift on SDSpolyacrylamide gels (SDS-PAGE) or by in vitro kinase assays. Phosphorylation sites on BRCA1 
fragments were defined by mass spectroscopy and peptide sequencing. The biological effect of lack of BRCA1 phosphorylation was analysed by cell viability and colony forming assays.

\section{Results}

BRCA1 was found to co-immunoprecipitate with ATM and ATM was found to co-immunoprecipitate with BRCA1 from HeLa cell nuclear extracts.

Gamma-irradiation of cells was found to cause endogenous BRCA1 to migrate more slowly on SDSPAGE, suggesting phosphorylation of BRCA1. This effect was not seen in ATM-deficient cells, but was restored by addition of an ATM expression vector.

Phosphorylation of glutathione-S-transferase (GST) -BRCA1 fusion proteins in vitro by ATM occurred mostly between amino acids 1351 and 1552. Mass spectroscopy of a fusion protein consisting of GST and BRCA1 residues 1021-1552, phosphorylated in vitroby ATM revealed two different phosphopeptides when analysed before and after phosphatase treatment. Peptide sequencing of these peptides indicated that serine 1423 and serine 1524 were phosphorylated.

Gamma-irradiation of cells expressing a BRCA1 fragment (residues 1351-1552) caused a shift in its mobility on SDS-PAGE, and this effect was accentuated by the co-expression of ATM. However, mobility of a BRCA1 fragment, identical except for the mutation of serines 1423 and 1524 to alanines (which cannot be phosphorylated) was only slightly shifted by gamma-irradiation, and this effect was not accentuated by expression of active ATM.

Introduction of wild type, full length BRCA1 into BRCA1-mutant HCC1937 cells decreased their sensitivity to gamma-irradiation by both cell viability and colony forming assays. However, introduction of a BRCA1 mutant (S1423A and S1524A) did not.

\section{Discussion}

This study indicates that ATM may be one of the kinases responsible for phosphorylating BRCA1 after gamma-irradiation. However, phosphorylation of BRCA1 in response to ultraviolet light, methylmethane sulfonate and hydroxyurea appears to be independent of ATM (Scully et al: Cell 1997, 90: 425-435 [Abstract]).

DNA repair is defective in both ATM- and BRCA1-deficient cells. As gamma-irradiation induces phosphorylation of BRCA1 by ATM, the DNA repair defect in ATM-deficient cells may be due in part to a lack of correct BRCA1 phosphorylation. Thus, these results may be relevant to the issue of the relative benefits of X-ray-based mammography screening for the early detection of breast cancer. 


\section{Additional information}

There is a commentary on this paper in the same issue of Science (Venkitaraman: Science 1999, 286: 1100-1102).

The predisposition of ATM heterozygotes to breast cancer is controversial (Fitzgerald et al: Nat Genet 1997, 15: 307-310 [Abstract]; Janin et al: Br J Cancer 1999, 80: 1042-1045 [Abstract]).

BRCA1 has also recently been reported to be phosphorylated at serine 1497 , probably by CDK2-cyclin E during late G1 phase, and/or by CDK2-cyclin A during S phase (Ruffner et al: Mol Cell Biol 1999, 19: 4843-4854 [Abstract]).

\section{References}

1. Cortez D, Wang Y, Qin J, Elledge SJ: Requirement of ATM-dependent phosphorylation of BRCA1 in the DNA damage response to double-strand breaks. Science. 1999, 286: 1162-1166. 